\title{
Analysis of sustainability aspects of the packaging deposit-refund system in Latvia
}

\author{
E. Dāce, I. Pakere \& D. Blumberga \\ Institute of Energy Systems and Environment, \\ Riga Technical University, Latvia
}

\begin{abstract}
In Latvia, for more than a decade, a container system for packaging waste segregation has been in a continuous process of development - starting with the first containers in the beginning of 2000s until now, when there are efforts made to provide containers to people living in rural areas. Although the regeneration targets set by EU are fulfilled by the existing system, it is still considered as not effective enough. In many cases the existing system is considered as economically and even environmentally unsustainable, but it is still maintained due to governmental pressure. At the same time, for about last five years hot discussions are held on implementation of packaging deposit system which would operate in parallel with the existing containers' system. Since there are too many controversial arguments from the stakeholders involved, an analysis is necessary to assess the sustainability aspects of implementation of the depositrefund system in Latvia. The paper presents the results of an analysis of the social, economic and environmental aspects. The results show that the depositrefund system has a positive influence on the environmental aspects, however the benefits gained have to be balanced with the system's costs and efficiency, which is hard to reach in Latvia because of small beverage drinks' consumption. Therefore, solutions have to be found to enhance the existing curbside containers' system rather than to introduce the deposit-refund system.

Keywords: deposit-refund system, packaging waste, sustainability, deposit fee, beverage drinks.
\end{abstract}

\section{Introduction}

Reduction of municipal waste has been an important issue in Latvia as large part of waste is deposited in landfills. Even if sorting rate of different waste materials 
increases with every year, still, according to Central Statistical Bureau of Latvia (CSB) [1] $46 \%$ of municipal waste was landfilled in 2010 . Up to $20 \%$ of municipal solid waste is compiled of used packaging materials. Different experiences from other countries show the way to increase recovery rates for packaging materials by introducing deposit-refund system (DRS). DRS means an extra payment for product which would be refunded after giving back the empty packaging unit. This system is mainly used for beverage drinks filled in different polyethylene terephthalate (PET) or glass bottles, as well as in aluminum cans. Packaging involved in DRS constitute on average $20 \%$ of all packaging waste.

In Latvia, the first curbside containers for separate waste collection system were set up in 2001, as reported by one of the operating producer responsibility organizations - Latvian Green dot [2]. Since then the regeneration rates for packaging waste have increased from about $28 \%$ in 2003 up to $47 \%$ in 2010 , fig.1. As it can be seen, there are inconsistencies in the data of regenerated waste amounts. Until 2006, the regulations No. 139 issued by the Cabinet of Ministers of the Republic of Latvia [3] were applied, however definitions and explanations on the terms 'recycling' and 'regeneration' were lacking, thus the enterprises submitted the data by their understanding. From 2006, European Parliament and Council Directive 94/62/EC on packaging and packaging waste [4] came into force, defining the terms and setting the regeneration targets binding to Latvia. Thus the data until 2006 are unlikely and inconsistent, whereas data from 2007 onwards are more believable.

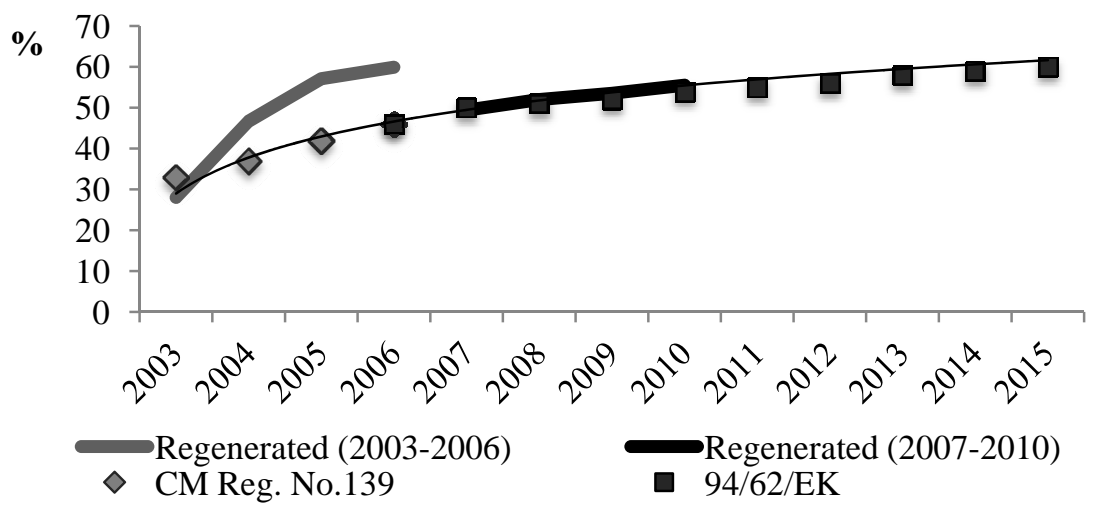

Figure 1: Targets of regeneration rates of the packaging waste according to regulations issued by the cabinet of ministers of the republic of Latvia (2003-2006) [3] and European parliament and council directive 94/62/EC on packaging and packaging waste (2006-2015) [4] and their performance in Latvia according to statistical reports on regenerated packaging materials [5].

It can be seen from Figure 1 that in 2010 percentage of regenerated packaging waste has exceeded 55\%. Nevertheless, the landfilled amount of waste is still very high. 
European Parliament and Council Directive 94/62/EC on packaging and packaging waste [4] requires 60\% regeneration rate for packaging waste in 2015. From the Figure 1 it seems that it would not cause difficulties to reach this level, however directive sets also fixed targets for recovery of different packaging materials, and until now Latvia is step behind these rates.

In order to assess whether an increase of the level of recycling is possible by using DRS in Latvia, a study by a company Price Waterhouse Cooper was conducted in 2008 [6]. Necessity of DRS, details on how the system will work and the costs and profits of the system were analyzed in the study. Until now this is the widest study on the implementation of the DRS in Latvia. Nevertheless, the study does not include an analysis of all sustainability aspects, i.e. social, environmental and economic.

As DRS has been applied in different countries, number of studies can be found on targets achieved for the waste reduction possibilities. However, the situation in other countries cannot be directly applied for analyzing the situation in Latvia, since waste management policy, as well as social, economic and environmental aspects for Latvia differ from other European countries.

According to the latest announcements from the government's representative Vesere [7] it is expected that in Latvia the implementation of the DRS could be started in 2015, therefore the aim of the present paper is to analyze the social and environmental aspects, as well as to estimate the costs of implementation of the DRS in Latvia.

\section{Methodology}

There are several parties involved in the DRS (producers, retailers, consumers, government and other), which make the system more complicated since every participant has different interests and needs. The DRS can gain the optimal result only in the case when all the parties are economically or emotionally motivated to take part in the DRS.

The basic aim of the system is to increase the level of recovery of packaging waste. As deposit added to the products has been paid by customers, they are interested to return the empty bottles and cans in order to get back the money spent. Producers are participating in the system as otherwise they are obliged to pay the natural resource tax per every packaging unit. If the tax is higher than costs of participation in the DRS, producers have a strong motivation to involve. Retailers can use the DRS as a marketing resource to attract customers. Whereas for government the DRS is an instrument to fulfill the binding targets set by EU.

Since there are so many stakeholders involved in the DRS, it is necessary to find a balance among interests and needs of all the interested parties from economic, social and environmental points of view.

\subsection{Social aspects}

In order to analyze the social aspects of the implementation of the DRS a couple of surveys were conducted at the beginning of 2012 - for consumers and 
municipalities. Consumers were surveyed in Riga (capital of Latvia) in four supermarkets of a company Rimi Latvia which has the largest food market network in Latvia. The supermarkets included in the study are located in different parts of the city. 125 valid answers given by both male and female of age between 18 and 62 were collected and analyzed. The questionnaire included items about packaging from consumer perspective (does it influence their choice, what happens when the product is unpacked etc.) to find out their viewpoint about implementation of deposit packaging and DRS.

In Latvia, municipalities are responsible for managing waste in their administrative territory, therefore municipalities are an important stakeholder of the DRS. At the beginning of 2012, a survey was conducted in order to find out the opinion of municipalities. The survey was conducted by preparing an online questionnaire sent out to all 119 municipalities of Latvia. Eighty-eight valid answers were received from municipalities of 7 major cities and 81 districts. The questionnaire included items about waste management system and its efficiency in municipalities, as well as factors preventing and motivating population to involve in the waste management system and waste sorting.

\subsection{Economic aspects}

The costs of the implementation of the DRS were determined by estimating the amount of beverage drinks (i.e. bottled water, soft drinks, beer and lightalcoholic cocktails) placed in the market. The existing and future consumption of beverage drinks was determined by assuming that it changes with the changes of gross domestic product (GDP). By using the projected data of products' consumption, as well as fraction of different packaging materials, an approximate amount of units of the deposit packaging placed in the market in 2015 onwards was estimated. Further, the estimated amounts of packaging units were used to assess the collection costs, which make the basis for payment's quantification to retailers.

When the packaging is collected, the refillable units are delivered to producers of beverage drinks, whereas one-way packaging is sold to recyclers. That forms the income of the operator. Besides the income from material sales, the operator also has income from the unredeemed deposits (sum of deposit fees for packaging that has not been returned by customer). However, the operator has also to cover the costs of retailers for collection of one-way packaging. In case of one way packaging, the balance between profit and costs of the operator is very important for optimal result. The deficit is covered by service charges made by producers. Operation costs of the operator are composed of a loan and interest payments, labor, transportation, maintenance, production and administrative costs.

The service charge shows the costs of packaging waste management that have to be covered by producers. The service charge can be compared to other alternative waste management systems to find the cheapest solution for producers. 


\subsection{Environmental aspects}

The environmental aspects were evaluated in terms of decreased energy consumption and related $\mathrm{CO}_{2}$ emissions, as well as diminishing waste littered in the surrounding environment. It was assumed that the energy savings would arise from recycling and reuse of the collected packaging material and utilizing it instead of the virgin material. Consumers' purchasing power would lower due to application of the deposit fee, thus decreasing the consumption of beverage drinks and the amount of packaging used with it. Thereby, also here the energy consumption and $\mathrm{CO}_{2}$ emissions would be decreased.

In order to estimate an influence on littering, a test was conducted to determine the composition of waste littered in Latvia. Starting from 2008, an environmental clean-up campaign is held once a year. During the campaign the litter is being collected in special garbage bags and delivered to the sanitary landfill sites. In this study, one landfill site was chosen, were the test was conducted. The composition of the collected garbage bags was analyzed by sorting their content into deposit packaging and other waste.

\section{Results and discussion}

\subsection{Social aspects}

Although in Latvia a curbside container system for segregated waste was started in 2001 [2], the results of the municipalities' survey have shown that more than fifth of municipalities (22\%) does not have any elements of the waste sorting system, $9 \%$ have just a few containers in a whole municipality, but $7 \%$ have only a drop-off point, fig. 2.

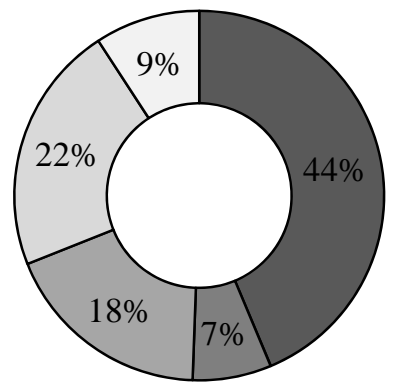

口Only curbside containers for segregated waste

口Only drop-off point

$\square$ Curbside containers for segregated waste and a drop-off point

$\square$ None

$\square$ Just a few containers throughout the municipality

Figure 2: $\quad$ Level of provided waste sorting system in municipalities of Latvia in 2012.

The results also show that only $9 \%$ of municipalities consider the existing curbside container system to be effective to increase the packaging recovery rates. The rest hold a view that the DRS would possibly (56\%) or definitely (31\%) be more effective for their municipality. This is also proved by the 
consumer survey, results of which show that lack of curbside containers and large distances to reach the containers are fairly important factors, which hinder from sorting the packaging waste. However inconvenience of sorting waste in the households is rather significant factor, thus stronger motivating instruments are necessary.

The results show that the strongest factors that would motivate the population to sort their packaging waste are convenient access to curbside containers and/or take-back points of DRS. Also an increase of waste management costs of unsorted waste would be a strong motivating factor.

According to the results of Eurobarometer survey conducted in 2011 [8], about $28 \%$ of the population in Latvia sort most of their waste for recycling. Whereas, the analysis of the results of consumers' survey show that in case if the DRS would be implemented the percentage of population sorting their packaging waste for recycling might increase up to about $80 \%$. Fifth of the consumers would be motivated to sort by the possibility to receive back the money spent, i.e. the deposit fee, whereas only $7 \%$ would sort for cleaner surrounding environment. $6 \%$ of the respondents would be motivated to sort only if it would not cause inconvenience, i.e. the take-back points of the deposit packaging would be easy accessible. However, all of the factors mentioned above are equally important for the majority of respondents (66\%). That confirms the necessity to find a balance among all the influencing factors - determination of an optimal amount of the deposit fee, providing convenient sorting facilities, as well as informing the society of the systems' positive influence on the environment.

The idea of DRS is that the deposit fee is added to the product packed in the deposit packaging and received back later when the packaging is delivered to the take-back point. That is, it used as an instrument motivating the consumer to return the packaging for recycling. However, it can also influence the consumers' purchasing power; thus, the choice of products.

As the results of the consumers' survey show, when choice is made between similar products, packaging can always (17\%) or sometimes (58\%) be a decisive factor for $75 \%$ of respondents. This is important, if deposit packaging is considered. The results show that $76 \%$ of respondents would prefer a product in the deposit packaging. However, for now there is a lack of information that would explain to the society that the DRS might cause also economic burden related to rise of the price of products.

Regarding the waste management costs, Eurobarometer [9] has reported results, which state that in Latvia $45 \%$ of population would prefer to include the cost of waste management in the price of products they buy. In order to assess the influence of the increased price of products, elasticity of demand of beverage drinks was considered, which shows the percentage of the demand's changes, if the price of the product changes by $1 \%$ (Andreyeva et al. [10]). The elasticity of demand for bottled water is 0.36 (Reizina [11]), for soft drinks - 0.79 (Andreyeva et al. [10]), whereas for alcoholic drinks - 0.38 (Fogarty [12]). It can be seen that elasticity of demand is lower for bottled water and alcoholic drinks than that of soft drinks. It means that changes of consumer prices have larger 
influence on the consumption of the soft drinks than on other drinks mentioned. It was found that depending on the amount of deposit fee, the price per $1 \mathrm{l}$ of alcoholic drinks will increase by $2.4-5.6 \%$, soft drinks - by $5.6-13 \%$, whereas bottled water - by $10 \%$ up to $25 \%$. That will cause the drop of consumption of the beverage drinks by $1.5-5 \%$, which will affect producers of the beverage drinks, since their income will decrease. It also explains why in Latvia producers strongly oppose the implementation of DRS. Besides, according to a study by Price Waterhouse Coopers [13] the producers' costs for packaging waste management would increase by $62 \%$ if compared to the existing system. Moreover, the Association of Small Breweries states that extra costs for breweries will reduce the ability to compete with other products that will not join the DRS.

The largest food retailers, on their side, support the DRS as it can attract new customers. The experience of other countries shows that in case if a retailer chooses to use reverse vending machine (RVM) for collection of the deposit packaging, then the deposit fee refunded for the empty packaging is mainly paid as a receipt that later can be used as a discount when purchasing products from the same retailer. If traders use such payment system, then DRS can be considered as a positive marketing activity.

However, the implementation of the DRS is more complicated for small retailers. As pointed out by the Latvian Traders' Association, DRS will significantly increase the retailers' costs. It will be necessary to install take-back points for empty packaging with extra employees. Also strict documentation will be necessary.

\subsection{Economic aspects}

There are several studies reporting the assessment of economic aspects of DRS [14-17], besides a few studies deal with analysis of impact from packaging DRS on consumers and producers [18-20].

The economic estimates show that large investments will be necessary to implement the DRS in Latvia - more than 20 million EUR will be required in the first three years. The annual costs of DRS are determined by the amount of deposit packaging placed on the market. The costs of retailers differ for manual and automatic collection. In case of automatic collection reverse vending machines (RVM) are used. In order to cover the costs of purchase, adjustment and maintenance each RVM needs to collect at least 1200 units of packaging per day. The retailers' costs of packaging collection are covered by producers in case of refillable bottles or by the operator in case of one-way packaging. The money paid to retailers for covering the collection costs of the packaging ranges between 27.6 and 29.6 EUR per thousand units of packaging for manual collection, and between 44.4 and 45.7 EUR per thousand units of packaging for collection with RVMs.

When the packaging is collected, the refillable units are delivered to producers of beverage drinks, whereas one-way packaging is sold to recyclers. Nevertheless aluminum composes the smallest part of deposit packaging both, by units and weight, it ensures the largest profit from sales to recyclers. This profit 
is one of the income sources for the operator of the DRS. Another source is from unredeemed deposits, i.e. the deposit fees of the packaging that has not been returned to the system. The balance between the operator's profit and costs is very important for optimal result. The service charges were estimated to find the amount of money producers have to pay per $\mathrm{kg}$ of packaging to cover the operator's deficit.

Now, when the curbside system is in operation, the producers of beverage drinks can choose to pay for the collection of their packaging by a natural resource tax to the government or by a contract price to a producer's responsibility organization (PRO), which ensures collection of packaging waste and exempts the contractor (producer) from the natural resource tax. Currently the most of the market (91.7\% of producers' generated packaging volumes in 2008) is covered by two PROs - Zaḷais punkts (Green Dot Latvia) and Zạāa josta (Green Belt) (Hogg et al. [15]).

For some materials the difference between the natural resource tax and the contract price is even tenfold, fig. 3. Since producers have two possible options, they mostly choose the cheapest one, i.e. to sign a contract with a PRO and pay the contract price (tariff) per each kilogram of used packaging material. Thus, in reality only minor part of producers pay the natural resource tax.

The estimates show that in case of operator's service charge (DRS), producers will have to pay more for PET and aluminum packaging than they do by having a contract with PRO. However, in case of glass packaging it would be more advantageous to pay the service charge since it is lower than any of PROs' contract prices. Thus the DRS can be considered economically feasible for producers only in case of glass packaging.

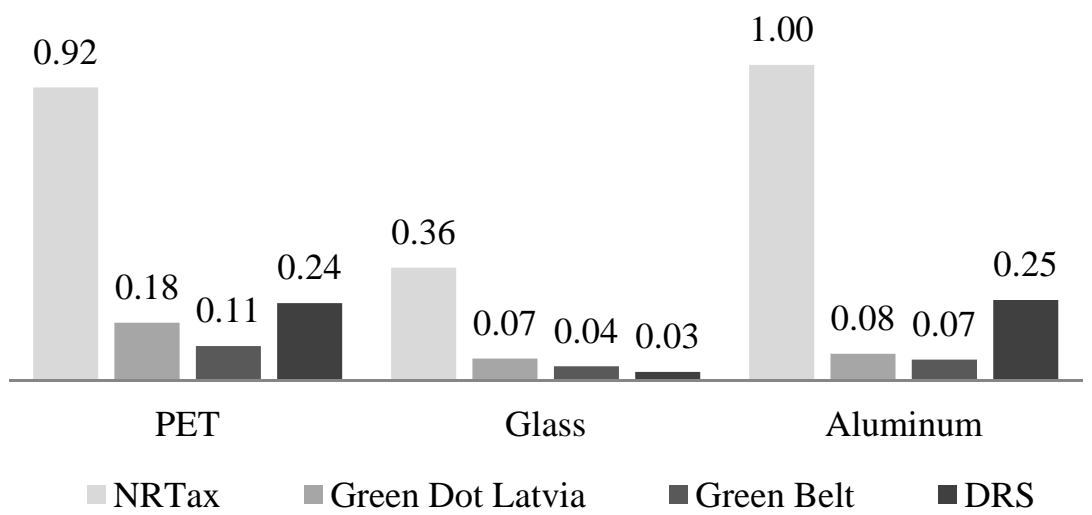

Figure 3: Charges for the packaging in Latvia in 2012, and the average service charges for deposit packaging in 2015-2020, in EUR/kg [21-23]. 


\subsection{Environmental aspects}

There are several environmental advantages that can be gained by implementation of the DRS. The most frequently mentioned is reduction of landfilled municipal waste, as well as reduction of littering which has been discussed in a number of studies [14, 24, 25]. Littering has been mentioned as one of the environmental problems that can be reduced by implementation of the DRS. In Latvia, littering is common along the roads, in parks and forests, in bus stops, as well as in territories of abandoned allotments. According to Yeh and Vaughn [26] the packaging of beverage drinks is often left on the roadways, parks and beaches, because people find it convenient to do so. DRS can help to solve the problem of littering by offering a motivational tool for consumers to bring the packaging to the collection point. The importance of the littering's reduction that results in cleaner surrounding environment has been pointed out by Hogg et al. [24]. Nevertheless, a report by Europen [25] argues that beverage containers make only $5-15 \%$ of littering in Europe. That was also confirmed by analyzing the composition data of littering collected during the clean-up campaign in Latvia. The results of the analysis show that the deposit packaging compiles only $11 \%$ of the total waste mass collected, or $28 \%$ of the total volume collected. Thus, by implementing the DRS the littering problem can be solved only partly.

The main aim of the DRS is to enhance the material recycling rates, thus saving energy and resources. Aluminum and PET are among the most required materials. According to Holmgren and Henning [27], it is possible to save up to $97 \%$ of energy by producing cans from secondary materials compared to production from bauxite ore. Production of PET from secondary materials saves $96 \%$, but glass - about $30 \%$ of energy. Depending on the recovery rates it is possible to save a considerable amount of energy by recycling the packaging waste (fig. 4).

As the figure shows, the largest amount of energy can be saved by recycling the PET packaging since the amounts produced and energy saved are higher than for aluminum and glass. The lowest energy savings can be achieved by recycling glass; therefore, more attempts should be driven towards reuse.

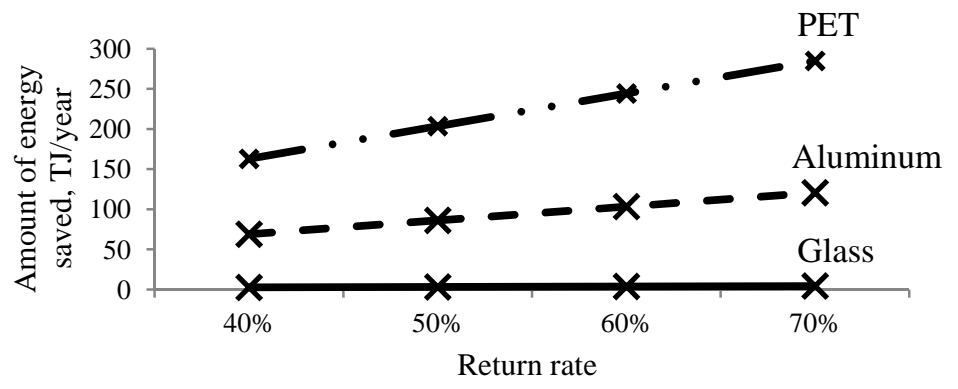

Figure 4: Amount of energy that can be saved depending on the material return rates (based on the packaging waste amount generated in Latvia in 2010). 
It has been estimated that by implementing the DRS the average fraction of packaging materials recycled would increase by $10 \%$ if the fraction of packaging returned would be at least $70 \%$. In that case almost 60TJ of energy could be saved annually (corresponding to the amount of deposit packaging in Latvia). Depending on the energy resource and efficiency of the equipment used it is possible to estimate the amount of $\mathrm{CO}_{2}$ emissions prevented. The experience of other countries [28-30] shows that the fraction returned can exceed 70\%, thus giving even greater energy savings.

\section{Conclusion and recommendations}

In Latvia, a curbside container system is in operation for packaging waste, however most of the municipalities are not satisfied with the existing system, since it develops too slowly. Besides the curbside container system does not motivate most of the population to sort their waste due to inconvenience caused by waste sorting in households and the distances they have to make to reach the containers. Since the EU's regeneration targets are binding to Latvia, solutions have to be found to enhance the existing curbside containers' system or to introduce a new system for packaging waste management. A deposit-refund system (DRS) to be started in 2015 is in consideration at the government level. However, also DRS has several disadvantages: (i) implementation of packaging DRS requires high costs and results with higher prices of products; (ii) deposit packaging contributes only about $20 \%$ to all packaging materials placed in the market, thus curbside collection system still needs to work together with DRS, which means maintaining two systems in parallel (including double transportation and higher $\mathrm{CO}_{2}$ emissions in the air).

There are also other aspects to be taken into account when considering the implementation of DRS. In order to ensure the systems' equal availability to all consumers, location of the take-back points has to be planned properly since it has a large influence on the systems' costs and efficiency. Proper decisions have also to be made on the types of packaging to be included in the system. The initial estimates show that the recovery rates will be larger than with the existing system, however it will also increase the producers' costs of packaging waste management. It is estimated that the DRS in Latvia will be feasible for beverage drink producers only in case of glass packaging.

The advantages provided by the DRS are the considerable increase of recovery rates of the materials included in the system and the amount of energy saved by recycling the materials instead of producing them from virgin raw materials. It has been estimated that even a slight increase in recovery rates can give a considerable decrease in the energy consumed, thus the $\mathrm{CO}_{2}$ emitted into the air. Also littering problems can be lessened. It was estimated that in Latvia PET and glass bottles and aluminum cans compile about $11 \%$ of the total litter.

The potential benefits have to be evaluated in relation to the costs of the system. It can be concluded that DRS can be feasible and sustainable in countries with large consumption of beverage drinks, where the 'per unit' costs are low. However, in order to find the optimal solution for Latvian conditions 
(improvements of the existing system, the existing system combined with the deposit system, or deposit system alone) it is necessary to develop a model that includes all sustainability aspects presented in a dynamic manner. In order to do that thorough sociological study is suggested to understand the human behavior, as well as analysis of the results of existing experience of DRS' implementation in other countries.

\section{References}

[1] Central Statistical Bureau of Latvia, database No. VIG04. Municipal and hazardous waste: collection and treatment, http://data.csb.gov.lv/ DATABASEEN/vide/Annual\%20statistical\%20data/14.\%20Natural\%20res ources\%20and\%20environmental\%20protection/14.\%20Natural\%20resour ces\%20and\%20environmental\%20protection.asp

[2] European Environment Agency, Statistical report on generated packaging waste and recovery of resources in the Republic of Latvia in 2003-2011 according to the European Commission Decision 2005/270/EC.

[3] Annual Report of the Latvijas Zalais punkts. Riga, 2009, http://www.zalais.lv/files/2010_09_13_lzp_parskats_eng.pdf

[4] Regulation No.139 of the Cabinet of Ministers of the Republic of Latvia "Regulations regarding volumes and time periods for recovery of packaging waste, procedures for submission reports and model forms of reports”. Latvijas Vēstnesis 52 (2627), 05.04.2002.

[5] Directive 2004/12/EC of the European Parliament and of the Council amending Directive 94/62/EC on packaging and packaging waste. Official Journal of the European Union L47/26, 18.2.2004.

[6] Analysis of implementation aspects of the packaging deposit-refund system, and development of preconditions for glass and PET bottles and aluminum cans [in Latvian]. Price Waterhouse Coopers, 2008.

[7] Vesere, R. Personal communication, 15 December 2011, Head of the Department of Environmental Protection, Ministry of Environmental Protection and Regional Development, Latvia.

[8] Attitudes of European citizens towards the environment, Special Eurobarometer 365. Eurobarometer, 2011.

[9] Analytical report: Attitudes of Europeans towards resource efficiency, Flash EB Series \#316. Eurobarometer, 2011.

[10] Andreyeva,T., Long, W.M. and Brownell, B.K., The Impact of Food Prices on Consumption: A Systematic Review of Research on the Price Elasticity of Demand for Food. American Journal of Public Health, 100 (2), pp. 216222, 2010.

[11] Reizina, V., Impact of economic situation on the changes in Latvia's inhabitant consumption expenditures. Scientific Journal of Riga Technical University, Economics and Business. Economy: Theory and Practice, Vol. 20, pp. 100-107.

[12] Fogarty J., The own price elasticity of alcohol: A meta-analysis. The University of Western Australia: Crawley, 2010. 
[13] Impact of one-way packaging deposit-refund system on the beverage drink industry in Latvia [in Latvian]. Price Waterhouse Coopers, 2010.

[14] Lavee, D., A cost-benefit analysis of a deposit-refund program for beverage containers in Israel. Waste Management, 30 (5), pp. 338-345, 2010.

[15] Hogg, D., Elliot, T., Croasdell, S., et al., Options and Feasibility of a European Refund System for Metal Beverage Cans. Final report. Eunomia, 2011.

[16] Mrozek, J.R., Revenue Neutral Deposit/Refund Systems. Environmental and Resource Economics, Vol. 17, pp. 183-193, 2000.

[17] Palmer, K., Sigman, H. and Walls, M., The Cost of Reducing Municipal Solid Waste. Resources for the Future, 1996.

[18] Numata, D., Economic analysis of deposit - refund systems with measures for mitigating negative impacts on suppliers. Resources, Conservation and Recycling, Vol. 53, p. 199-207, 2009.

[19] Onuma, A. and Saito, T. Some Effects of Deposit-Refund System on Producers and Consumers. Keio Economics Society Discussion Paper Series (KESDP), 2006.

[20] Kulshreshtha, P., and Sarangi, S., No return, no refund: an analysis of deposit-refund systems. Journal of Economic Behavior and Organization, Vol. 46, pp. 379-394, 2001.

[21] Natural Resource Tax Law. Latvijas Vēstnesis, No 209 (3367), 29 December 2005.

[22] Tariff of Latvijas Zaļais punkts, http://www.zalais.lv/lv/uznemumiem /tarifu-kalkulators/iepakojumu-tarifu-kalkulators/

[23] Tariff of SIA Zaḷā josta and other PROs, http://www.zalajosta.lv /lat/jaunumi/?doc=128

[24] Hogg, D., Fletcher, D., Elliot, T. and Eye, M.V., Have We Got the Bottle? Implementing a Deposit Refund Scheme in the UK. Eunomia Report, 2010.

[25] Better rules for a better environment: Modern Beverage Container Policy. Europen, 2009.

[26] Yeh, C.-N. and Vaughn, P.J., Consumer's Behavior under Mandatory Deposit System. International Advances in Economic Research, 14(4), pp. 472, 2008.

[27] Holmgren, K. and Henning, D., Comparison between material and energy recovery of municipal waste from an energy perspective. Resources, Conservation and Recycling, Vol. 43, pp. 51-73, 2004.

[28] Dansk Reursystem, http://www.dansk-retursystem.dk/content/us/

[29] Eesti Pandipakend, http://www.eestipandipakend.ee/

[30] Returpack, http://www.returpack.se/en/ownership-structure/ 